\title{
Mobile and Adaptive Learning Application for English Language Learning
}

Samir Bourekkache, Smart Computer Science Laboratory, Computer Science Department, University of Biskra, Biskra, Algeria iD https://orcid.org/0000-0003-2038-6257

Okba Kazar, Smart Computer Science Laboratory, Biskra University, Biskra, Algeria

\begin{abstract}
Mobile learning is considered a new phase of e-learning which gives the opportunity to learn more effectively and efficiently. In addition, the use of mobile devices for leaning is more sophisticated and more useful. The m-learning has become available anywhere and anytime for all students and professors. Moreover, the features of these mobile devices include ease of use in every place and time, very reasonable cost for students, and the ability to communicate through the internet or mobile networks, encouraging the development of many kinds of methods and systems. Now, a huge number of applications, in several domains, are oriented to this kind of mobile device. Researchers have been exploiting this technology to enhance the knowledge of learner (especially foreign languages learning). In this paper, the author proposed an educational system that provides the opportunity for students to learn English language outside the classroom and encourages them to get actively involved in their own learning processes.
\end{abstract}

\section{KEYWORDS}

Adaptive Learning, Android, Android Studio, Educational Content, English Learning, Learning Process, M-Learning, Mobile Devices

\section{INTRODUCTION}

At the beginning of the 21 st Century, the society world knows several new features, characteristics and needs such as: rapid rate of technological and social change rapid lifestyle and the people are occupied the most time. These technological advancements allow fast communications and information processing that support new social patterns. Therefore, the researchers and communities have to take into account the new interest and preferences, work patterns, and opportunity.

According to the Global Digital report, almost two-thirds of the world's population currently has a mobile phone, and more than half of this uses smartphones; in addition, over half of the world's web traffic currently comes from mobile phones (Wearesocial, 2017). So, the authors are experiencing the huge spread of the mobile devices (smartphones, tablets ...etc) around the world (low-cost of mobile phone) (Mostafa and Said, 2017). Also the spread of portable information and communications technology (ICT) with the relatively recent advent of small, portable mobile devices that provide 
telephone, Internet, and data storage, mobile telephony, removable memory chips, diaries, email, Web, basic word processing and spreadsheets, and data input, storage, and transfer.

The new social structure is deeply influenced by the mobile information and communication technologies. In the domain of Learning, the researchers have exploited the new technologies: Mobile technology, wireless networks (WiFi access in all public sectors schools and companies ...etc), information and communication technology (ICT) as a mean to improve deeply the ways of communication and learning. These technologies are the key to strengthening and facilitating learning and teaching in the 21 st century. As a result, this emerging technology and mobile devices reveal a new way of learning known as Mobile learning (M-Learning) (Mostafa and Said, 2017). In M-learning environments, the learning process becomes more sophisticated, faster and efficient with a minimum of problems: gain of time, economy of transport costs and accommodation, always available, no specific schedule of learning, flexibility, interactivity... etc (Jenni, 2013).

Using a mobile learning process, the learners are isolated and sometimes disoriented. In addition, the learners are generally heterogeneous so that they have different abilities, preferences, cultures, characteristics, intellectual capacities...etc. Thus, Mobile learning system should provide a set of features to be adaptable with new methods: ease of use, reuse and adaptation of the learning content, take into account the needs and levels of learners (backgrounds, objectives, levels of abilities...etc), personalized content, contextual representation of user's information (Ramya and Madhumathi 2017).

Learning English language is a difficult process especially in the case of the absence of human teacher (learners will deal with an application in their mobile devices). English language has spoken side, written side and grammatical side. Therefore, every application for learning languages must cover all these sides efficiently. In addition, Listening plays an important role in communication and it is considered as the first skill to be acquired early before other skills, especially with children who are a good listener and grasp the language even before they start to speak. Learners need to improve their listening skills in order to understand natural English speech. In this paper, the authors aim to define a new approach for M-learning and develop the M-learning system in the Android operating system for English learning. Then the authors test this mobile application on a group of students of computer science department, second year license.

The rest of the paper is organized as follows: section 2 presents related works. Section 3 discusses the differences between M-learning and E-learning and expresses the characteristics of M-learning. In Section 4, the authors present the modeling of the proposed approach and explain the role of its parts (modules). The section 5 presents in details of the proposed system by expressing the functionalities of each sub module and their communication with each other. In section 6 , the authors present some important scenarios of the system. The next section is devoted to present the validation of the proposed system and the used tools for developing the prototype to test it and present the results of the proposed approach. Section 8 concludes this paper.

\section{RELATED WORKS}

Several works have proposed many approaches, systems and applications for M-learning in order to improve the way to acquire knowledge. In Senthil (2015), the author proposed mTeacher, a mobilebased self-assessment system to assess the knowledge level of learners in their area of interest and to assist by giving feedback. The major objective of this study is to propose a framework and to evaluate the system and to explore the level of learners' acceptance towards the system. In this study the five factors (result of the learners, satisfaction level of learners, convenience of learners, feedback about skill level, assisting the learner) are investigated whether they have positive influence on mTeacher or not. The feedbacks of both teachers and learners were highly motivating.

The authors of Ronald et al (2018) discussed the use of mobile applications in university education. Their main goal is to investigate if university students are using or would like to use mobile phones and apps, in particular educational apps. Therefore, the authors aim to identify the mobile apps used 
for educational purposes by students in Kenyan universities, and to investigate the apps and services considered useful by students. From the perspective of universities and mobile application developers, the authors provides insights about the potential demand of educational mobile apps for use in Kenyan universities, and in turn other universities across Africa. As a result, they gathered the information from the study and showed an insight on which apps to adopt or implement in university education.

In the work of Berns et al (2015), the authors presented mobile applications that improve the learning of the Foreign Language (German language course at a Spanish University). They expressed the application: "Guess it! Language Trainer" which plays a role of support for students' independent language learning outside the classroom. Moreover, they showed the important of this app to encourage the students to get actively involved in their own learning processes. In addition, they discussed the possibility to use the stored information (in the system) by the teacher in order to retrace and assess students' language learning.

The author of (Olga, 2015) focused on the adaptation of formal education to people's technologyuse patterns, their technology-in-practice. For this aim, she used the ubiquitous and mobile technologies. The main objective of this work is to integrate language learning practices which are informal environment together with formal education through the use of mobile technology. This study investigates the technical, pedagogical, social and cultural challenges involved in the development and design of mobile approach.

\section{From E-Learning to M-Learning}

E-learning knew, in its early phases, an important lack of sophisticated technical functionality which could offer possibilities for interaction with society and its contexts, whereas, the mobile technology offers this opportunity of interaction. Mobile learning can be considered as a subset of E-learning, the emerging potential of mobile technologies helped to indicate M-learning (Jenni, 2013; Olga, 2015). M-Learning is characterised by flexible learning: just enough, just in time, just for me.

There are several attempts to define the mobile learning that focus only on the mobility of the device but also the mobility of learners and learning itself. There are four important aspects of the M-learning: technologies, people, learning and context. One of the definitions is "It's E-learning through mobile computational devices such as: Palms, Windows CE Machines, even the digital cell phone" (Quinn, 2000; John, 2007). Another definition which show the mobility of learners and learning "any sort of learning that happens when the learner is not at a fixed, predetermined location, or learning that happens when the learner takes advantage of the learning opportunities offered by mobile technologies" (Ramya and Madhumathi 2017; Olga, 2015).

E-Learning has come to define any dissemination of educational knowledge over the Internet. This makes E-Learning a subset of technology-based training and M-Learning is often described as occupying a sub-space within the E-Learning space, which is in turn a sub-part of digital learning (Youcef et al, 2013). Since M-learning is a kind of special E-learning, it has also the same characters as general E-learning. From the viewpoint of educational technologies, common characters of E-learning lie in the following main indicators (Anani et al, 2008):

- Support of synchronous and/or asynchronous education;

- Support of on-line and/or off-line mobile learning;

- Support of user's location (on-campus, off-campus);

- Access to learning materials and/or administrative services.

The pedagogical document is the most important entity in every learning system, but developing and indexing it, generally, takes time and sometimes it is a hard task. Moreover, the learners are not homogeneous and so they have different levels, learning styles and preferences. The pedagogical document should be accurate to the majority of learners according to their preferences and styles. Also, the learner is isolated in the educational system (no human tutor); he interacts directly with the 
pedagogical document. Thus, this latter must contains additional information to use it in the appropriate case and time. For this aim, the authors propose that the pedagogical document is done by a group of authors, to reduce the construction time and improve the quality of relevant information. In any platform of learning, the pedagogical document is an essential object that's why it needs to be well structured and well indexed for easy retrieval of different information within this document and also the system can reuse it in the relevant cases.

\section{MODELLING OF THE PROPOSED APPROACH}

The objective of the design phase is to answer the question « how to model and do the system », by describing an internal architecture of the system and by presentation of all possible components that form this system (processed information, performed treatment, obtained results, constraints to be respected, ...etc.).The structural and functional aspects are the key elements of a good design; they must be defined to support the implementation and maintenance. The authors propose a general architecture of the M-learning system that is based on four main components as it is shown in Figure 1.

Because M-Learning is seen as an extension of E-Learning, so the authors use the mobile device as a "tutor" for learning of basics of English language.

The "domain model" represents the needs and the knowledge of the educational field of study that will be taught. Also, an educational system must have the "learner model" that gives a complete and accurate description as possible of all aspects of the characteristics, preferences, background and behaviors of the learner. In this M-learning system, the authors should define the "pedagogical module" that represents the different methods and learning styles that seem appropriate for the system and learners. These methods and styles are defined according to many dimensions: cognitive, behavioral, emotional, psychological and sociological. Finally, "the interface" allows and facilitates the communication of the learner with the educative mobile system.

\section{Detailed Architecture of the Proposed M-Learning System}

This architecture is based on three models: the domain model, the pedagogical model, and the learner model. The detailed description of this architecture is depicted in Figure 2.

Figure 1. General architecture of the proposed M-learning system

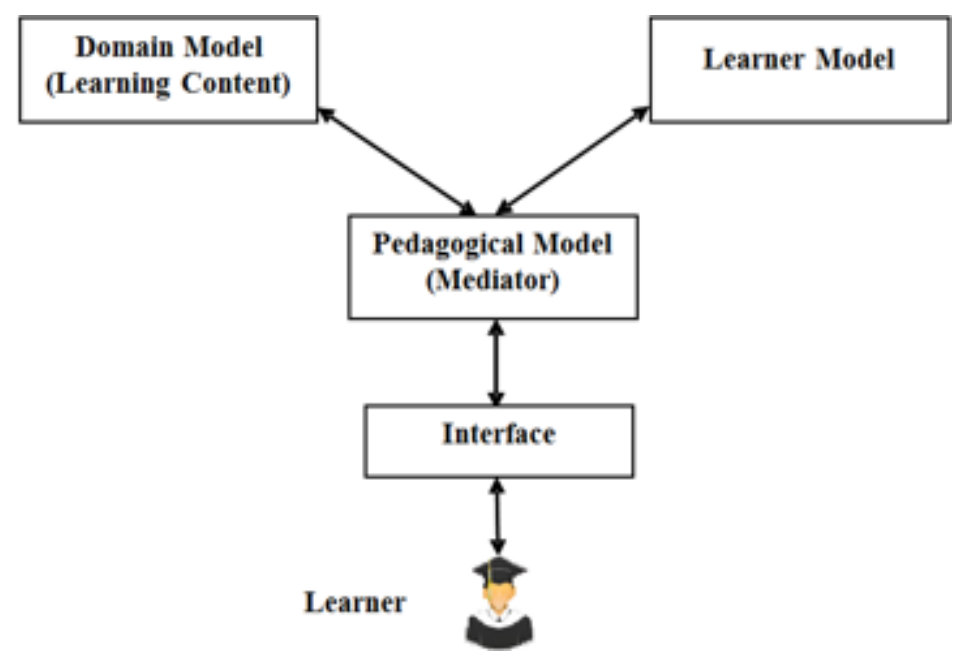


Figure 2. Detailed architecture of the M-learning system

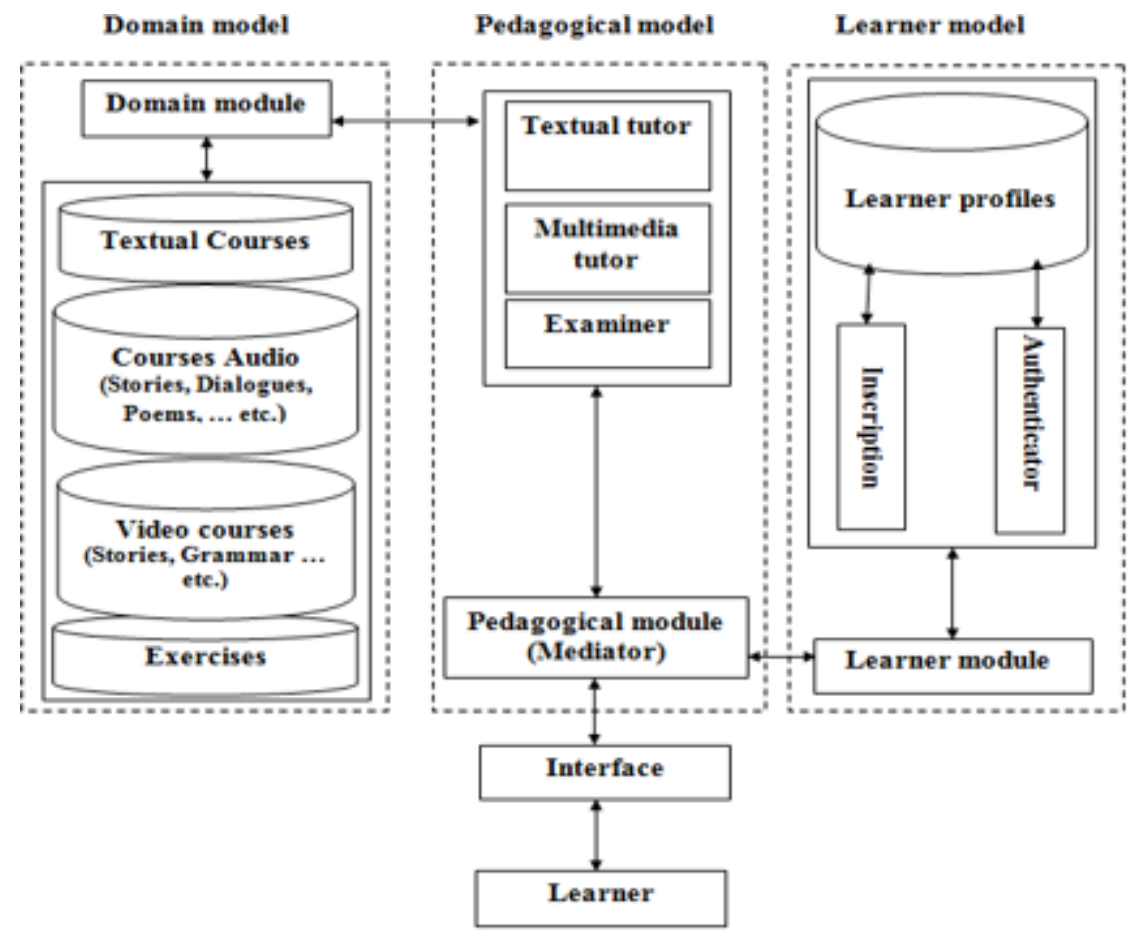

\section{Learner Interface}

This component can be seen as a mediator or a point of communication between the devices of the learner and the system. In the proposed system, the interface must have a mechanism for interactive dialogue with the learner to allow this latter to understand what he is about to learn.

\section{Pedagogical Model}

It is responsible of the learning process; it acts as a teacher in the classroom. It is based on four main components.

\section{The Textual Tutor}

It is considered as a teacher who can react with the system. It provides the appropriate courses to the learner. Also, this component is based much more on the textual course. It performs the following tasks:

- Organizes courses for studying;

- Presents the courses (textual courses).

\section{Multimedia Tutor}

It is the component that handles the audio and video learning course, this kind of courses is very important in the field of languages (speaking, listening). It is responsible for:

- Presents Audio / Video Courses (stories, songs, etc.);

- Presents dialogues with their texts (audio and textual). 


\section{Examiner}

The main objective of this component is to evaluate the learner through the multilevel tests. It has several tasks:

- $\quad$ Prepares and display tests;

- Corrects the responses of the learner;

- Calculates and evaluate the test result from the responses of the learner.

\section{Pedagogical Module (Mediator)}

It is the heart of the system. It is also seen as a mediator between all the system components. Through the mediator, all the system components (interface, learner model, domain model, educational model) can communicate. It is a stationary module that has the role of monitoring the operations of the system.

\section{Domain Model (Learning Model)}

This model contains two components.

\section{Courses Database}

This database contains three kinds of courses (each kind is used in different case):

- Textual courses: Contain the basic courses of English language (alphabet, family relationships and grammar,... etc.);

- Multimedia courses: Contain the multimedia courses (audio and video) such as: dialogues, stories and some educational songs and poems;

- Exercises: It contains all tests for each course. The tests are multiple-choice (question multiple choice) allowing automatic correction. There are three levels of questions: Level 1 (beginner), Level 2 (medium) and Level 3 (Advanced).

\section{Domain Module}

This module is responsible for managing the courses and the tests, and then it sends the courses to the tutor module (text and multimedia) and exercises to the examiner module.

\section{Learner Model}

The learner model contains four components.

\section{Inscription Module}

It allows the subscription of new learners in the mobile learning system and validates the correctness of the learner information.

\section{Authenticator}

It controls the connection authorization of users by checking the user name and password entered by the users with the registered ones in the database. These two components use a database to store the information of each learner (by the inscription module) and to check the connection of users to the system (by the authenticator).

\section{Learner Profile}

It is a database that contains all necessary information about the learner (personal information: name, age, level, preferences, characteristics .... etc.). 


\section{Learner Module}

This module is responsible for managing registrations (by inscription module) and also manage authentication (by authenticator).

\section{FUNCTIONING OF THE SYSTEM}

In this section, the authors describe the functioning of the main components of the system. For presenting the functioning of the system and the different scenarios, the authors use the UML language for modeling the interactions between the components of the system.

\section{Scenario 1: Registration of a New Learner}

- Firstly the learner must install and run the application on his mobile device;

- The interface displays the home page and two commands "Sign In» for registering and "Log In" for login. If the learner is new then it must choose "register";

- The interface displays the fields of registration (Username, Password, Age, Name, preferences ...etc.), then the student must fill out all the fields;

- Then, the learner clicks on "Sign In" (register), the interface sends a request containing the information of fields to the pedagogical module, then to the learner module;

- Learner module transfers the request and the entered information to the inscription module;

- The inscription module verifies the existence of the identifier in the database and checks the correctness of the information. In the case of any error, it sends a request by the learning module and the pedagogical module which passes it the interface to display a message that tells the kind of error. In the case of success it creates a new profile of the learner in the database "learner profiles" and informs the learner.

\section{Scenario 2: Launching Courses}

- After the connection of the learner, the interface displays the available courses for each learner according to his level preferences characteristics;

- The learner chooses one of the available courses;

- The interface sends the request to the pedagogical module which passes it to the tutor. The tutor uses many roles to define which course is more appropriate for this learner, and then send the identifier of the course to the domain module;

- The domain module selects the demanded course from the database;

- The domain module sends the selected course to the tutor which sends it again to the interface through the mediator;

- The interface displays the course to the learner.

\section{IMPLEMENTATION AND RESULTS}

The authors have used the Java language for developing the prototype. The used environment is the "Eclipse" which is considered as IDE. The use of SDK Android and ADT (Android Developer Tools), allow the development of Android application (now the authors can use Android Studio). In Addition, SQLite allows the creation and manipulation of database. Also, they use AVD Manger to run and test the application in this emulator (AVD) under windows. Finally, for the design of the application interfaces, the authors used Photoshop CS6.

For the test of the application, the authors chose the computer science students of second years license. Before starting the learning process the authors gave them a test to know the real level of each 
Figure 3. Scenario of subscription of new learner

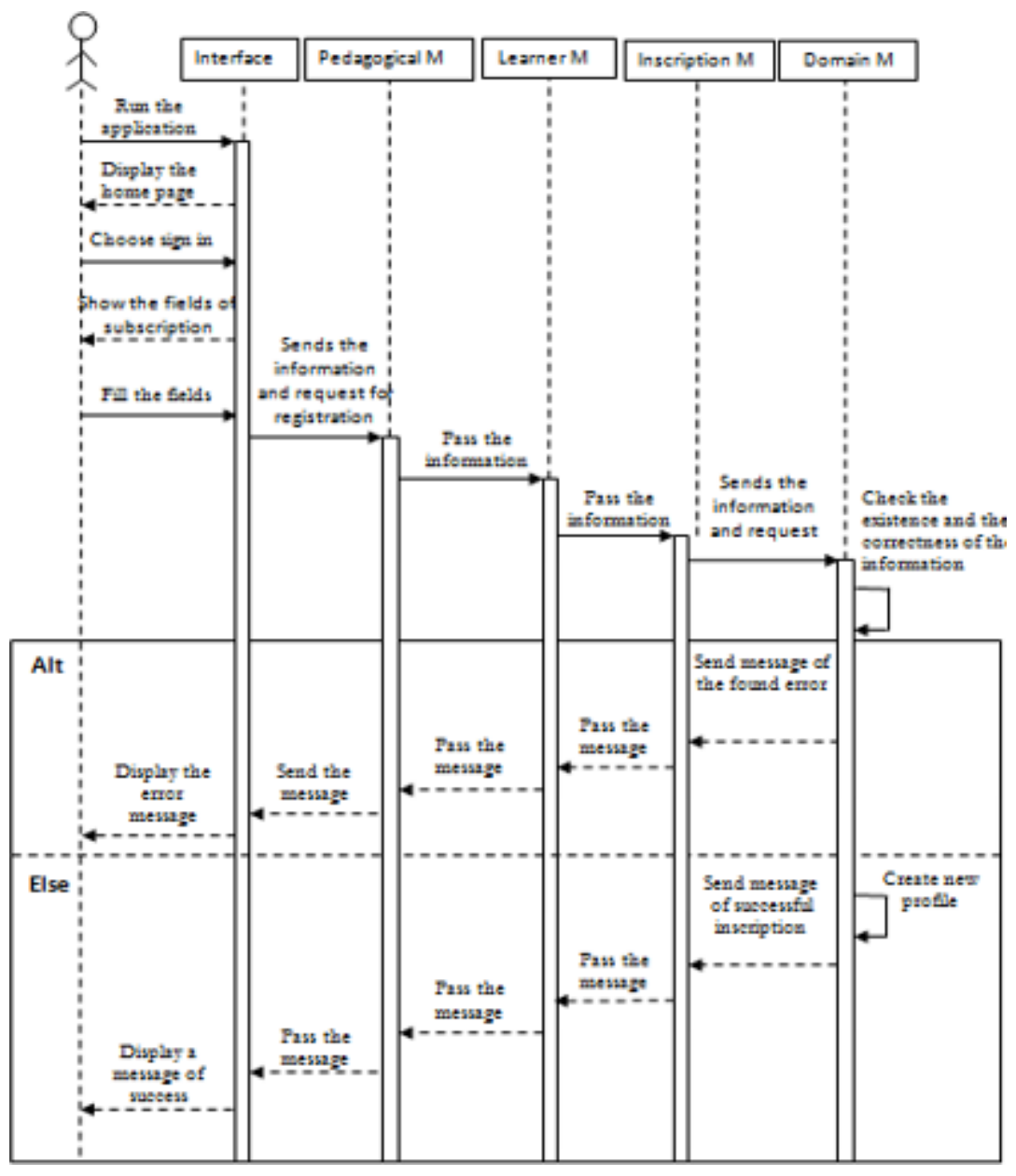

student (learner). Then, they ran the application on their mobiles and started learning. After a period of time, they performed the evaluation (test) to pass to the next level. The authors have notices that:

- The majority of students prefer to learn using mobile application $(76,92 \%)$ because their advantages and availability;

- $\quad 85 \%$ of the students are interested to learn English;

- More than the half of the students prefer to use the audio and video materials for this learning;

- $\quad 78,92 \%$ of the learners prefer to learn using dialogs and interactive processes;

- During the process of learning, the majority of learners chose the chat as a way of learning English (76,69\%);

- $\quad 92,31 \%$ of the learner used the research option in the application;

- $\quad 70 \%$ of the learners used the application more than 15 minutes in each use;

- After the test, they notice that the learners who focused on the audio and video materials have the chance to pass the test more than the others;

- The dialogs and the interactive processes (chat, discussions) help the learners to understand more efficiently; 
Figure 4. Scenario of launching a course

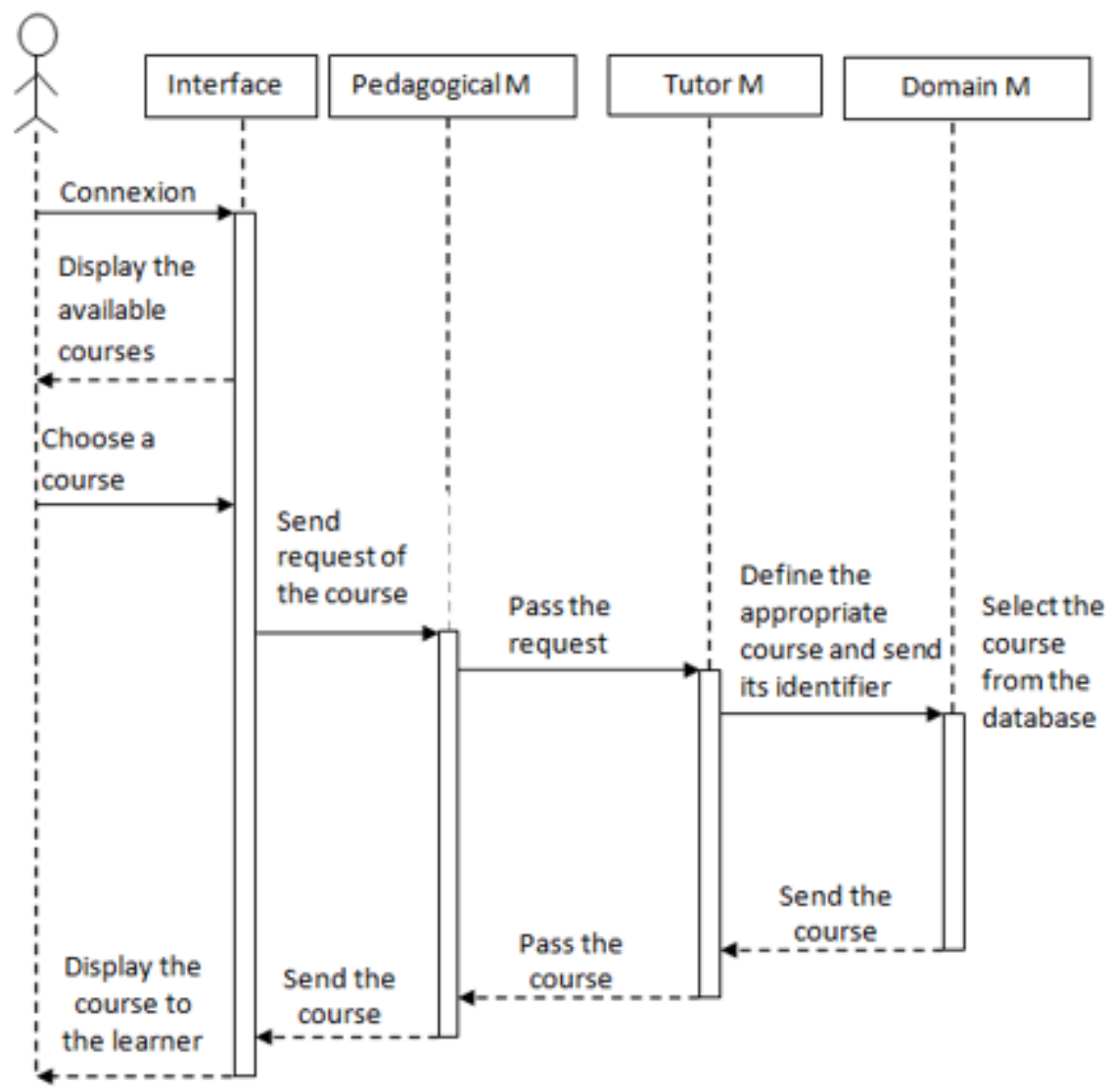

Figure 5. The interface of the mobile application for English learning
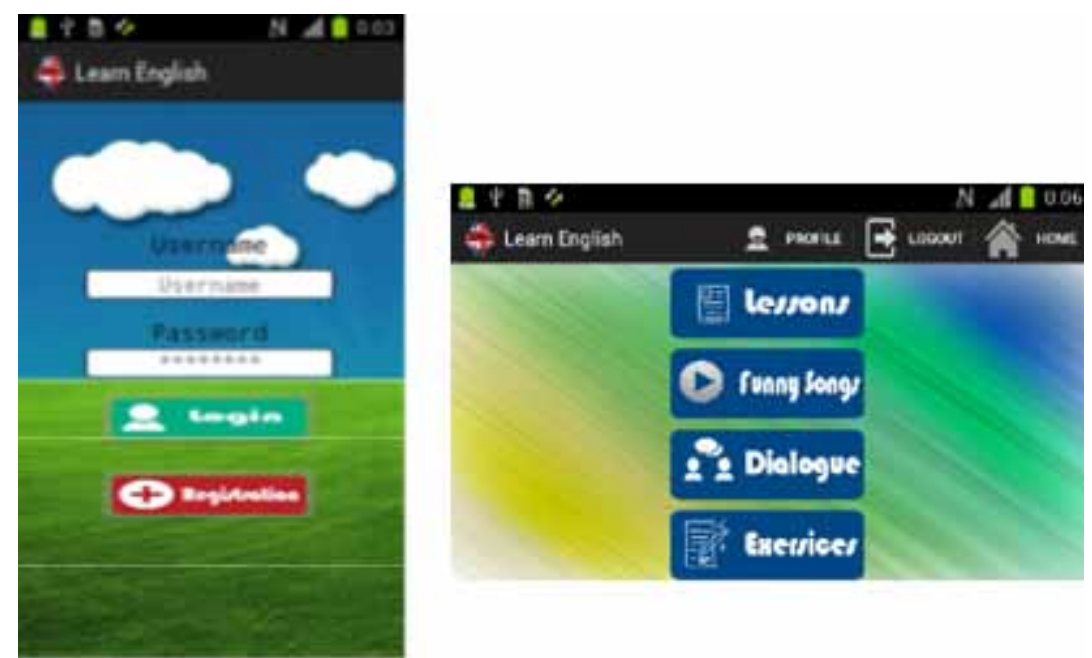
- Listening plays an important role in communication. Listening is considered as the first skill to be acquired early before other skills, especially with children who are a good listener and grasp the language even before they start to speak. Learners need to improve their listening skills in order to understand natural English speech.

\section{CONCLUSION}

Learning English requires several skills to develop (Speaking, listening reading, and writing). Thus, one must use several techniques and strategies to ensure that learners will understand the educational content. In this paper, the authors presented an educational application on Android for mobile learning. The objective of the proposed system is offering a mobile environment for teaching the basics of English language. Moreover, one of the main goals in a mobile learning environment is to provide the right and accurate resource at the right time and best way for each learner. For this aim, the authors have developed a system that tries to meet the needs of heterogeneous learners (needs, levels, preferences... etc.). M-learning allows the learners to learn anywhere (during traveling, free time, at home, in the work, Street ... etc.). The proposed system has some limitations that it is necessary to improve in future works. The authors received some feedbacks from the learners especially about enriching the features of the application such as the functionality of the interfaces and integration of communication between the learner and the teacher. Also, the authors will attempt to provide several adaptation strategies to give the opportunity to different students with different backgrounds and levels. Another, perspective of this work is to use mobile agents to improve the aspect of learning and learning adaptation (the adaptation of content and strategy, presentation adaptation ...etc.). Finally, the authors have to compare the proposed system with other existing systems to show the strong and weak points of it. 


\section{REFERENCES}

Anani, A., Zhang, D., \& Li, H. (2008). M-learning in review: Technology, standard and evaluation. Journal of Communication and Computer, 5(11).

Berns, A., Palomo-Duarte, M., Dodero, J. M., Ruiz-Ladrón, J. M., \& Calderón Márquez, A. (2015). Mobile apps to support and assess foreign language learning. Proceedings of the 2015 EUROCALL Conference, 51-56. doi:10.14705/rpnet.2015.000309

Jenni, R. (2013). Mobile Learning - a Review of Current Research, Reports of the Department of Mathematical Information Technology Series E. Educational Technology, FI-40014.

John, T. (2007). Defining, Discussing, and Evaluating Mobile Learning: The moving finger writes and having writ. International Review of Research in Open and Distance Learning, 8(2).

Mostafa, A., \& Said, A.(2017). Students' Attitudes Towards the Use of Mobile Technologies in e-Evaluation. International Journal of Interactive Mobile Technologies, 11(5).

Naji, S., \& Abdul Razak, Y. (2011). Students' Awareness and Requirements of Mobile Learning Services in the Higher Education Environment. American Journal of Economics and Business Administration, 3(1), 95-100. doi:10.3844/ajebasp.2011.95.100

Olga, V. (2015). Design and use of mobile technology in distance language education (PhD thesis). Orebro University School of Business, Studies in Informatics 11, Sweden.

Quinn, C. (2000). mLearning: Mobile, Wireless, in-your-pocket Learning. Retrieved on 05/05/2018 from http:// www.linezine.com/2.1/features/cqmmwiyp.htm

Ramya, G., \& Madhumathi, P. (2017). Review on Use of Mobile Apps for Language Learning. International Journal of Applied Engineering Research, 12(21), 11242-11251

Ronald, O., \& Luisa, M. (2018). Mobile application in university education: the case of Kenya. The International Journal of E-Learning and Knowledge Society, 14(1).

Senthil, V. (2015). MTeacher: a tool for self-assessment and providing personalized assistance to M-learners: a framework and evaluation. The International Journal of E-Learning and Knowledge Society, 11(1).

Weraresocial. (2017). Digital in 2017: Global overview. Retrieved from https://wearesocial.com/ blog/2017/01/ digital-in-2017-global-overview

Yousef, M., \& Hamideh, Z. (2013). Mobile Learning for Education: Benefits and Challenges. International Journal of Computational Engineering Research, 3(6).

Samir Bourekkache received his PhD degree from the Biskra University, Algeria in 2014. He is an Assistant Professor and a researcher at computer science department of Biskra University. He is interested to formal methods, semantic Web and approaches, artificial intelligence, MAS, adaptive e-learning techniques, mobile and ubiquitous learning, and security.

Okba Kazar was born at Biskra (Algeria) in 1962. He obtained his magister degree in 1997 from the Constantine University (Algeria) working on artificial intelligence field. He obtained his PhD degree from the same university in 2005. He is member of editorial board of some Journals. He is published more than 260 papers in international journals and communication in international conference. He participated as session chair in international conferences, he also publish a book "Manual d'Intelligence artificielle" and five chapters book. Professor KAZAR is currently full professor at computer science department of the University of Biskra, which he contributed to its founding and director of the Smart computer science laboratory (LINFI). His main research field is artificial intelligence, he is interested to the multi-agents systems and their applications, PHM in medical and industrial fields, ERP, advanced information systems, Web services, semantic Web, bigdata, internet of things and cloud computing and information communication technologies. 